\title{
REVIEW
}

\section{Foxtail millet: nutritional and eating quality, and prospects for genetic improvement}

\author{
Lu HE ${ }^{1}$, Bin ZHANG ${ }^{1,2,5}$, Xingchun WANG ${ }^{2,3,5}$, Hongying $\mathrm{LI}^{1,2,4,5}$, Yuanhuai HAN $(\bowtie)^{1,2,4,5}$ \\ 1 College of Agriculture, Shanxi Agricultural University, Taigu 030801, China \\ 2 Institute of Agricultural Bioengineering, Shanxi Agricultural University, Taigu 030801, China \\ 3 College of Biosciences, Shanxi Agricultural University, Taigu 030801, China \\ 4 Key Laboratory of Loess Plateau Crop Gene Resources and Germplasm, Ministry of Agriculture, Taiyuan 030001, China \\ 5 Shanxi Key Laboratory of Genetic Resources and Genetic Improvement of Minor Crops, \\ Shanxi Agricultural University, Taigu 030801, China
}

\begin{abstract}
Foxtail millet is a minor yet important crop in some areas of the world, particularly northern China. It has strong adaptability to abiotic stresses, especially drought, and poor soil. It also has high nutritional value. Foxtail millet is rich in essential amino acids, fatty acids and minerals, and is considered to be one of the most digestible and non-allergenic grains available and has significant importance for human health. Given foxtail millet's ability to adapt to abiotic stresses associated with climate change, it is more important than ever to develop breeding strategies that facilitate the increasing demand for high quality grain that better satisfies consumers. Here we review research on foxtail millet quality evaluation, appearance, cooking and eating quality at the phenotypic level. We review analysis of the main nutrients in foxtail millet, their relationships and the biochemical and genetic factors affecting their accumulation. In addition, we review past progress in breeding this regionally important crop, outline current status of breeding of foxtail millet, and make suggestions to improve grain quality.
\end{abstract}

Keywords foxtail millet, grain quality, quality evaluation, breeding for quality

\section{Introduction}

Foxtail millet (Setaria italica), a member of the family Poaceae, is one of the oldest cereal crops. There is ample evidence showing that foxtail millet was domesticated from the wild species green foxtail (Setaria viridis) 11000

Received April 7, 2015; accepted May 8, 2015

Correspondence: hanyuanhuai@163.com years ago in northern China ${ }^{[1]}$. Nowadays it is mainly cultivated in China and India, but is also produced on a smaller scale in South Korea, North Korea, Japan, Russia, Australia, France and the United States for human food, stockfeed or industrial uses ${ }^{[2]}$. Foxtail millet has some important agronomic characteristics such as high water use efficiency and drought resistance, tolerance to soil of low nutrient availability, strong adaptability and good yield stability. It was once regarded as more important than rice, wheat and beans ${ }^{[3]}$. Yields vary from 1200 to $6750 \mathrm{~kg} \cdot \mathrm{hm}^{-2}$, depending on the soil fertility, rainfall and cultivar $^{[4]}$.

In China, millet is generally consumed as porridge, sometimes prepared in the same way as rice either as a mixture with rice or just millet. Foxtail millet porridge at breakfast and/or evening meals is preferred by most people in northern China. Recently, a range of new millet products have become available ${ }^{[5]}$, such as drinks ${ }^{[6]}$, convenient and nutritious instant millet powder ${ }^{[7]}$ and other compound foods ${ }^{[8]}$. These are good examples of how new products of high nutritional value can be developed from foxtail millet. Development in processing of foxtail millet, and the other millets, and their potential as foods for different groups with special nutritional needs have recently been reviewed by Saleh et al. ${ }^{[9]}$.

With the improvement in living standards and dietary composition, people gradually aspire to a more varied and healthy diet. In recent years, the high nutritional value of foxtail millet has received considerable attention in China. Hulled foxtail millet is rich in nutrients including essential amino acids, fatty acids and minerals. It is suitable for individuals suffering from diabetes mellitus due to its low glycemic index ${ }^{[10]}$. Foxtail millet quality can be analyzed from several different perspectives, including nutritional quality, appearance quality and eating quality. However, it 
has not been studied as comprehensively as the major crops. Here we review research on foxtail millet quality and identify areas for future research to develop strategies for breeding for improved quality.

\section{Research on foxtail millet quality at the phenotypic level}

\subsection{Quality evaluation}

Foxtail millet is one of the grains favored by consumers in China, and selection for high quality has become a key area for breeding. This requires the development of recognized evaluation criteria for quality. At present there are two evaluation methods, using either sensory evaluation or chemical analysis ${ }^{[11]}$. The Millet Crop Expert Committee of China formulated the millet sensory evaluation method as a percentile system. The marking breakdown comprises 40 points for commodity quality ( 25 points for color and 15 for consistency), 60 points for eating quality (10 points for fragrance, 10 for sensory quality and 40 points for palatability $)^{[12]}$. More recently, researchers have been exploring improved, more objective, evaluation criteria. Li et al. ${ }^{[1]}$ using Jingu 21 as a reference cultivar, graded millet color, fragrance, palatability, viscosity and retrogradation at seven levels, and evaluated the quality based on comprehensive analysis of the different aspects, making the sensory evaluation more objective and consistent.

One of the most commonly used methods to evaluate millet quality is the analysis of chemical components. The Hebei Academy of Agriculture and Forestry Sciences ${ }^{[13]}$ proposed the high quality millet evaluation standard based on testing and analyzing numerous cultivars. Millet can be divided into two quality grades depending on indices of the contents of protein, crude fat, vitamin B, amylose, gelatinization temperature and gel consistency (Table 1). The Millet Crop Expert Committee of China applies this method so that experts can have a consensus to identify high quality millet cultivars and guide breeding strategies for improvement.

The sensory evaluation component of the percentile system is intuitive and easily performed. The downside is the difficulty in maintaining a uniform standard. Errors associated with the subjective nature of human evaluation are inevitable. As a control measure, professional members can join the assessment team in the assessment process, strictly adhering to a set of unified operation rules. The testing method for chemical analysis is scientific and precise, therefore the results are more objective. However, the cost of analysis is high and the measurements are complex and require specialist equipment.

Wang et al. ${ }^{[14]}$ integrated the features of the above two methods with people's evaluation of foxtail millet quality for palatability, marketability and nutrient content, they added yield and field performance as evaluating indicators and used this information to select 86 high quality cultivars. In addition to protein, fat and amylase content, selenium and tannin content and the taste of the porridge were added to the assay indices. Integrating the many factors which contribute to millet quality into a single system could help to evaluate millet quality more comprehensively.

\subsection{Research on appearance quality}

Most publications about appearance quality of foxtail millet have dealt with seed color and millet color. The Chinese Crop Germplasm Resources Information System (CCGRIS) holds a total of 3573 foxtail millet accessions with seeds showing 26 different colors, such as white, yellow, orange, brown, red, black and gray. Among the accessions in CCGRIS, 1708 accessions have yellow seeds, accounting for $48 \%$ of the total accessions, followed by $21 \%$ white and $19 \%$ light yellow. Some of the representative panicle colors, seed colors and millet (after seed hulling) colors are shown in Fig. 1. Evaluation of 3562 accessions identified 16 millet colors. Yellow millet accessions account for $77 \%$, followed by light yellow $(13 \%)$, golden $(4 \%)$ and white $(4 \%)$ accessions. Some accessions with special colors are also recorded in the database, such as orange (cv. Baishagu), dark gray (cv. Dulongjiang) and yellowish gray (a yellow manna from South Africa).

Appearance of millet is the first attribute that consumers use to evaluate foxtail millet quality. As reflected by the high proportion of yellow millet among the CCGRIS collections, yellow millets are generally preferred by the consumers. Important factors affecting consumers' perceptions are: grain color, color consistency and percentage of broken millet ${ }^{[2]}$. High quality millets should be consistent in size and color with very few or no broken grains and the

Table 1 Quality standards for high-quality foxtail millet

\begin{tabular}{|c|c|c|c|c|c|c|c|c|c|}
\hline \multirow[t]{2}{*}{ Grade } & \multirow[t]{2}{*}{ Protein $/\left(\mathrm{g} \cdot \mathrm{kg}^{-1}\right)$} & \multirow[t]{2}{*}{ Crude fat $/\left(\mathrm{g} \cdot \mathrm{kg}^{-1}\right)$} & \multirow[t]{2}{*}{ Vitamin $\mathrm{B} /\left(\mathrm{mg} \cdot \mathrm{kg}^{-1}\right)$} & \multicolumn{2}{|c|}{$\begin{array}{c}\text { Amylose content/ } \\
\left(\mathrm{g} \cdot \mathrm{kg}^{-1} \text { defatted samples }\right)\end{array}$} & \multicolumn{2}{|c|}{$\begin{array}{l}\text { Gel consistency/ } \\
\mathrm{mm}\end{array}$} & \multicolumn{2}{|c|}{ Alkali nitrate index } \\
\hline & & & & $\mathrm{N}$ & G & $\mathrm{N}$ & G & $\mathrm{N}$ & G \\
\hline First & $\geqslant 125$ & $\geqslant 46$ & $\geqslant 7.0$ & $140-170$ & $\leqslant 20$ & $\geqslant 150$ & $\geqslant 180$ & $\geqslant 3.5$ & $\geqslant 3.0$ \\
\hline Second & $\geqslant 118$ & $\geqslant 42$ & $\geqslant 6.5$ & $171-200$ & $\leqslant 50$ & $\geqslant 115$ & $\geqslant 180$ & $\geqslant 2.5$ & $\geqslant 3.0$ \\
\hline
\end{tabular}

Note: N, non-glutinous; G, glutinous. The data are sourced from the local standard in Hebei Province, China: DB/1300 B22 13-90, 1990, which is adopted as a national standard for grading the millet quality of approved foxtail millet cultivars. 
(a)

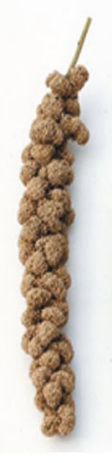

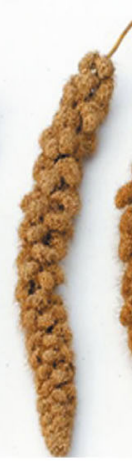

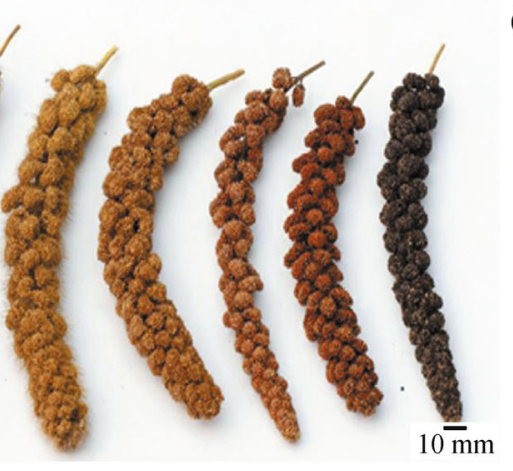

(b)

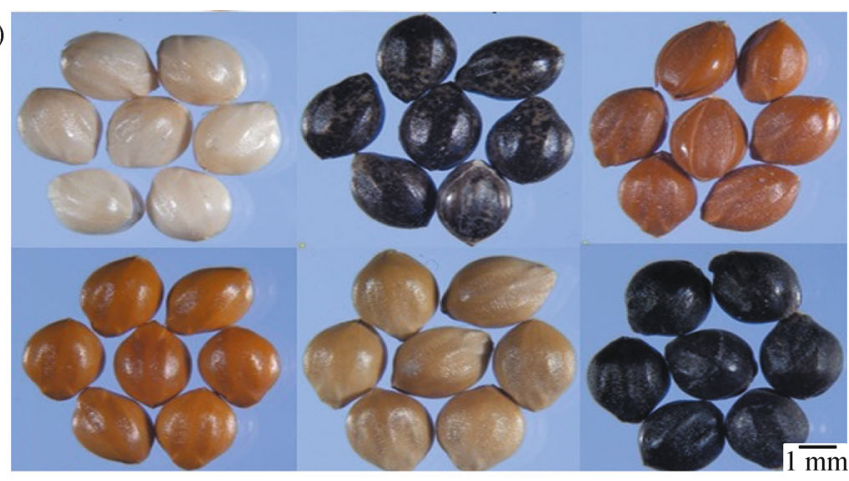

(c)

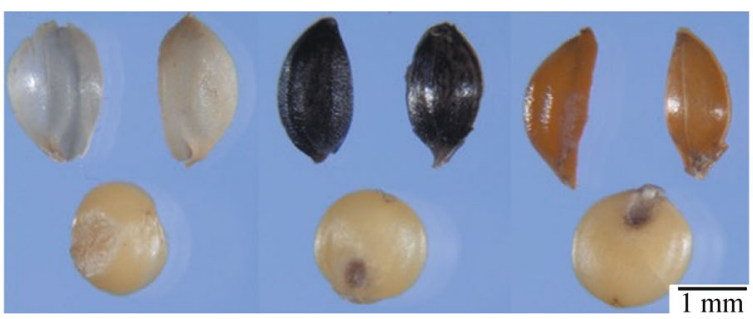

(d)

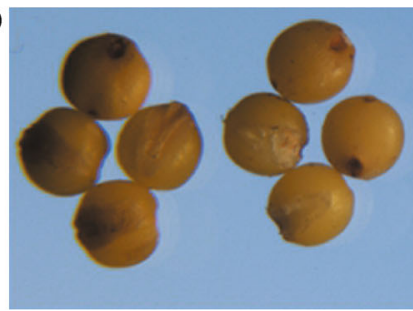

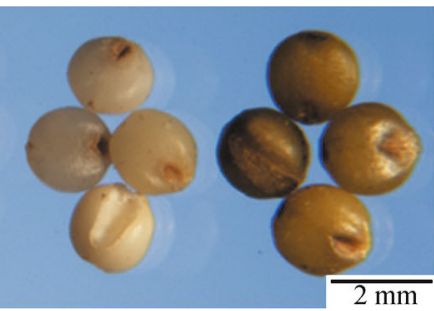

Fig. 1 Different colors of foxtail millet. (a) Panicles; (b) grains; (c) husks; (d) millets.

milled millet should have a fresh fragrance, produced principally by aldehydes and hydrocarbons ${ }^{[15]}$.

The yellow pigments in millet are mainly zeaxanthin, cryptoxanthin and xanthophyll ${ }^{[16]}$. These pigments show high thermostability and resistance to oxidoreduction, but are sensitive to light and acids ${ }^{[17,18]}$. The content of yellow pigment is $5.4-19.6 \mathrm{mg} \cdot \mathrm{kg}^{-1}$ in yellow millet, but $10.1-$ 16.4 and $1.1-2.5 \mathrm{mg} \cdot \mathrm{kg}^{-1}$ in gray millet and white millet, respectively ${ }^{[19]}$.

Millet color has a significant positive correlation with fragrance, color and palatability of cooked millet; the yellower the millet, the stronger the flavour, and hence the better the quality of the millet cultivar ${ }^{[20]}$. Interestingly, millets generally appear to turn yellower after alkaline cooking (with alkaline tap water or after adding sodium bicarbonate), but the mechanism has not been determined.

Inherent genetic variation affects the appearance quality of foxtail millet, but the production area is also relevant, due to the influence of ecological factors on quality. The appearance quality of foxtail millet from the North China summer millet region (including Anyang, Baoding, Shijiazhuang) is generally better than that from the North-west China spring millets region (Chifeng, Datong, Taiyuan, Lanzhou and Yan'an), which has a lower proportion of good quality millet. However, exceptions exist, for example, foxtail millet from Fenyang in the spring millet region is considered to have a particularly acceptable appearance ${ }^{[19]}$. The appearance quality of millet from different production locations in the same seasonal region also show clear differences, for example, in the summer millet region, the proportion of high quality millets in Shijiazhuang is higher than that in Baoding and Anyang ${ }^{[19]}$.

\subsection{Research on cooking and eating quality}

Cooking quality refers to the time required to cook millet porridge, with rapid cooking considered to be advantageous. Generally speaking, the cooking time of good quality cultivars is about $15 \mathrm{~min}^{[2]}$ and is generally assessed quantitatively by comparing content and molecular weight of amylose and amylopectin, gel consistency and gelatinization temperature ${ }^{[21]}$. It is generally accepted that if the amylose content is medium to low (90$\left.130 \mathrm{~g} \cdot \mathrm{kg}^{-1}\right)$, the gel consistency is medium to hard $(60-75$ $\mathrm{mm}$ ) and the gelatinization temperature is medium to low $\left(58-63^{\circ} \mathrm{C}\right)$, the millet is of good cooking quality ${ }^{[2,22]}$.

Quantitative analysis of gel consistency is based on the length of paste in a horizontal test tube after a certain amount of milled-millet is cooked, cooled down and laid level. Gel consistency is significantly negatively correlated with both amylose content and gelatinization temperature ${ }^{[22]}$.

The gelatinization temperature of amylose is commonly estimated using the alkali digestion method, which gives an indication of gelatinization temperature ${ }^{[23]}$. The higher the alkali digestion value, the lower the gelatinization temperature. Specifically, the gelatinization temperature is high when the alkali digestion index is among grades 1 to 3 , grades of 3.1-4.5 correspond to medium level gelatinization temperature, and grades higher than 4.5 are an indication of low level gelatinization temperature. There are specific relationships between gelatinization temperature and millet amylose content, cooking quality and palatability ${ }^{[23]}$. Gelatinization temperature is positively correlated with amylose content; if the gelatinization temperature is high, the millet requires more water and 
time to cook, which reduces cooking quality and palatability.

Eating quality is one of the most important aspects of foxtail millet quality, and the color, flavour and taste of cooked millet or the porridge reflect eating quality. The three indicators of millet cooking quality mentioned above are critically important for millet eating quality. Cooked millets of high amylose content are dry, fluffy, dark and show a high degree of retrogradation, whereas millets of low amylose content are sticky, glossy, soft and delicious $^{[2,24,25]}$.

The fragrance is one of the key factors affecting consumer choice of millet products. Volatile flavor compounds in millet have been extracted, isolated and identified using solid-phase micro-extraction and gas chromatography-mass spectrometry, with a total of 51 compounds identified ${ }^{[26]}$. Aldehydes and hydrocarbons are the major volatile groups. Aldehydes account for $41 \%$ of total volatile compounds. Considering that the threshold for sensing aldehydes by humans is low, aldehydes probably make the most important contribution to the flavour of cooked millet. The important aldehydes identified include saturated aldehydes such as pentanal, hexaldehyde, nonanal, decanal and unsaturated aldehydes such as (E, E)-2, 4-decadienal and others. Hydrocarbons account for $33 \%$ of total volatile compounds. Since the sensing threshold for hydrocarbons is high, these may have less influence on the flavour of millet, but a high content of pentadecane and hexadecane in particular may be important in overall flavour. In addition to the two groups above, 1-octene-3-alcohol, 2-nonanone and 2-amylfuran naphthalene, which have been confirmed as important flavour components in rice, and may also affect the flavor of millet porridge ${ }^{[26]}$. Based on the above results, Liu et al. ${ }^{[27,28]}$ analyzed the influence of water used for cooking and compared the volatile flavor compounds between porridges made from non-glutinous and glutinous millets, revealing that fewer volatile components are detected with increasing water addition. The absolute content of major volatile constituents is higher in glutinous millet porridge compared to non-glutinous millet porridge. Further identification of the key volatile components responsible for the aroma of millet and their characteristics is essential for the future improvement of millet.

\section{Biochemical aspects of foxtail millet quality}

The crude protein content of 2058 accessions of foxtail millet recorded in CCGRIS is $80-219 \mathrm{~g} \cdot \mathrm{kg}^{-1}$ and the differences are related to differences in cultivar and growing conditions ${ }^{[29,30]}$. For example, foxtail millet of high protein quality is produced at increased latitude and altitude, or in red and loess soils ${ }^{[31]}$. The protein content of foxtail millet is higher than that of maize, rice and sorghum, and the content of two essential amino acids, methionine and tryptophan, are the highest among cereal crops $^{[32]}$. As in maize and wheat, the main storage proteins in foxtail millet include albumen, globulin, prolamin and glutelin ${ }^{[33]}$. The overall content of amino acids, excluding lysine, is higher in foxtail millet than in rice, wheat and maize by $41 \%, 65 \%$ and $51 \%$, respectively ${ }^{[34]}$. The most abundant amino acids in foxtail millet are glutamate, leucine, alanine, proline and aspartic acid ${ }^{[30,35]}$. Eight of the essential amino acids (isoleucine, leucine, lysine, methionine, phenylalanine, threonine, valine, tryptophan) are present in foxtail millet, with the content of lysine varying the most, followed by methionine and valine ${ }^{[35,36]}$. The lysine content is often so low that it is hard to measure. The application of combined N, P and K fertilizer can be effective in promoting the accumulation of amino acids and thus significantly improving the nutritional quality of millets. In this respect the effect of $\mathrm{K}$ fertilizer is particularly apparent ${ }^{[37]}$.

Fat content is related not only to nutritional quality, but also to appearance and eating quality of foxtail millet. The crude fat content of 2038 accessions of foxtail millet in CCGRIS is within the range of $12-62 \mathrm{~g} \cdot \mathrm{kg}^{-1}$. However, some studies report fat content as high as $80 \mathrm{~g} \cdot \mathrm{kg}^{-1[38]}$ and as low as $11 \mathrm{~g} \cdot \mathrm{kg}^{-1[39]}$, and there is considerable variation between different production areas. For example, the average fat content of foxtail millet cultivars in Jilin is $50 \mathrm{~g} \cdot \mathrm{kg}^{-1}$, followed by $45 \mathrm{~g} \cdot \mathrm{kg}^{-1}$ in Shanxi, whereas in Gansu and Henan the average fat contents are lower, 44 and $41 \mathrm{~g} \cdot \mathrm{kg}^{-1}$, respectively ${ }^{[40-43]}$. Foxtail millet contains both saturated and unsaturated fatty acids, with unsaturated types accounting for $84 \%-88 \%$ of total fatty acids ${ }^{[39]}$. The main fatty acids are palmitic acid, stearic acid, oleic acid, linoleic acid, linolenic acid and arachidic acid, with 47\%$77 \%$ of the fat being linoleic acid ${ }^{[38,44]}$. In foxtail millet bran, the content of linoleic acid accounts for as high as $67 \%$ of total oils ${ }^{[45]}$. As linoleic acid and linolenic acid are essential fatty acids, cultivars with a higher content would be nutritionally desirable, however, excess linolenic acid in foxtail millet may affect storage stability ${ }^{[42]}$.

Carbohydrate content accounts for $75 \%$ of foxtail millet nutritional components by weight. There is little variation in carbohydrate content between foxtail millet cultivars ${ }^{[46]}$. It consists of reducing sugar, starch, cellulose and other minor components, with starch as the main form of carbohydrate ${ }^{[47]}$. Research on the structure, characteristics and function of starch has been more comprehensively studied than other carbohydrates, probably because the structure and properties of starch directly affect eating quality and processing quality of millet. Starch granules in millet are mostly polygonal and less ovoid in shape and show varietal variation in size ${ }^{[48]}$. Aspects used to evaluate the physicochemical properties of millet starch include shape and size of starch granules, amylose content, iodine 
blue value, solubility and swelling power, pasting properties (peak time, peak viscosity, hot paste viscosity, cold paste viscosity, breakdown value, setback value and stability ratio) and retrogradation properties. Recently, the Rapid Visco Analyzer with its flexibility, simplicity and small sample requirement has proved a useful tool for studying the quality of cereal grains ${ }^{[20,25]}$. Compared to maize, millet starch has greater agglutination stability, higher swelling power and gelatinization temperature and poorer freeze-thaw stability ${ }^{[49]}$. Millet starch is constructed from amylose and amylopectin. The amylose content ranges from 140 to $250 \mathrm{~g} \cdot \mathrm{kg}^{-1}$ in most foxtail millet cultivars, which is higher than maize and influences millet cooking quality in terms of flexibility, glossiness, glutinosity and fragrance. Millet starch content is affected by growing conditions, sowing date and cultivation techniques. For example, it decreases with an increase in latitude and altitude ${ }^{[31]}$. For summer millet cultivars, sowing in spring increases the amylose content, but reduces the amylopectin content ${ }^{[50]}$. What is more, in arid areas, controlled irrigation can promote the synthesis and accumulation of millet starch, and also reduce the gelatinization temperature of $\operatorname{starch}^{[51]}$. Resistant starch (RS), a kind of starch that escapes digestion in the small intestine of healthy individuals, aroused wide attention recently for its health benefits. In foxtail millet, the RS content varies among different cultivars. The RS level of yellow foxtail millet $\left(82-146 \mathrm{~g} \cdot \mathrm{kg}^{-1}\right)$ is higher than that in white types $\left(75-134 \mathrm{~g} \cdot \mathrm{kg}^{-1}\right)^{[52]}$. Dietary fiber content in millet is 2.5 times more than in rice and ranges from 11 to $48 \mathrm{~g} \cdot \mathrm{kg}^{-1}$ as determined by the acid-alkali detergent method ${ }^{[44]}$. Millets with high fiber and complex carbohydrate content are thought to be beneficial in controlling diabetes mellitus. A study showed that $80 \mathrm{~g}$ per day of a mix of foxtail millet, wheat semolina, black gram and selected spices in a diabetic diet for four weeks improved glycol-lipemic control ${ }^{[53]}$. Gluten-free fiber-rich cookies made of foxtail millet flour and copra meal flour of high quality and overall acceptability to consumers ${ }^{[54]}$.

As in other crops, foxtail millet absorbs minerals from the soil and these are essential to the plant itself and by extension, in humans who consume it. The contents of $\mathrm{Ca}$ $\left(227 \mathrm{mg} \cdot \mathrm{kg}^{-1}\right), \mathrm{Mg}\left(1593 \mathrm{mg} \cdot \mathrm{kg}^{-1}\right), \mathrm{Cu}\left(4 \mathrm{mg} \cdot \mathrm{kg}^{-1}\right), \mathrm{Fe}$ $\left(25 \mathrm{mg} \cdot \mathrm{kg}^{-1}\right)$ and $\mathrm{P}\left(2430 \mathrm{mg} \cdot \mathrm{kg}^{-1}\right)$ in foxtail millet are higher than those in rice; $\mathrm{Zn}\left(23 \mathrm{mg} \cdot \mathrm{kg}^{-1}\right)$ content is also higher than that in rice, wheat, maize and sorghum ${ }^{[39]}$. Mineral content in foxtail millet varies between cultivars and production areas. Both factors have a significant effect on Fe content. Mg content is only significantly affected by cultivar and Se content is only significantly affected by geographical origin ${ }^{[55]}$.

Selenium is one of the essential trace elements, functioning as an antioxidant, anti-aging agent and also has implications for the preventions of cancer and cardiovascular disease ${ }^{[55,56]}$. The range of selenium content in foxtail millet is $0.01-0.10 \mathrm{mg} \cdot \mathrm{kg}^{-1}$ and the average content is $0.07 \mathrm{mg} \cdot \mathrm{kg}^{-1[57]}$. Some landraces and cultivars with higher selenium content have been identified. For instance, the selenium content of cv. Jigu 21 reaches $0.19 \mathrm{mg} \cdot \mathrm{kg}^{-1}$, the highest recorded in China ${ }^{[58]}$.

Foxtail millet is also rich in vitamins, including vitamin $\mathrm{A}, \mathrm{B}_{1}, \mathrm{~B}_{2}$ and E. Its vitamin $\mathrm{A}\left(1.9 \mathrm{mg} \cdot \mathrm{kg}^{-1}\right)^{[34]}$ and vitamin $\mathrm{E}\left(43.5 \mathrm{mg} \cdot \mathrm{kg}^{-1}\right)$ contents $^{[44]}$ are higher than those of rice, wheat and maize. Foxtail millet is also rich in carotene, the precursor of vitamin A with $1.2 \mathrm{mg} \cdot \mathrm{kg}^{-1}$, a value twice as high as in maize ${ }^{[39,44]}$. Vitamin $\mathrm{B}_{1}$ content $\left(5.7 \mathrm{mg} \cdot \mathrm{kg}^{-1}\right)$ is nearly 1.7 times as high as in rice and maize, Vitamin $B_{2}$ content $\left(1.2 \mathrm{mg} \cdot \mathrm{kg}^{-1}\right)$ is slightly lower than in sorghum ${ }^{[39]}$. Recently, a survey of the folic acid content in millets of 247 cultivars and landraces from three different ecological regions of Shanxi revealed an average content of folic acid of $1.5 \mathrm{mg} \cdot \mathrm{kg}^{-1}$, ranging between 0.37 and $2.37 \mathrm{mg} \cdot \mathrm{kg}^{-1[59]}$.

\section{Research on foxtail millet quality at the molecular level}

In recent years, research on foxtail millet at the molecular level has intensified. The genome sequence of foxtail millet has been completed both in China and in the $\mathrm{USA}^{[60,61]}$, which has stimulated further research. The genome size is about $400 \mathrm{Mb}$, with about 30000 genes annotated. The population genetic diversity of foxtail millet has been extensively investigated ${ }^{[62-65]}$. Both $\mathrm{SNPs}^{[66]}$ and microsatellites ${ }^{[67-69]}$ have been developed and utilized as molecular markers. In addition, some novel marker types such as miRNA-based ${ }^{[70]}$ and transposable elements-based markers ${ }^{[71]}$ were developed along with construction of web-based databases ${ }^{[70-72]}$ for the access of the foxtail millet research community. A haplotype map of genomic variations has been proposed ${ }^{[66]}$. There has also been progress in studying the molecular mechanism of diseases $^{[73]}$ and other stresses especially drought tolerance ${ }^{[74-77]}$ and genes related to flowering have also been identified ${ }^{[78]}$. In addition, genetic transformation systems for foxtail millet and its wild relative Setaria viridis have been established and are being optimized ${ }^{[79,80]}$. Two transformation methods, particle bombardment ${ }^{[81,82]}$ and Agrobacterium-mediated transformation ${ }^{[79,83]}$ have been used successfully to generate transgenic plants in foxtail millet and the transformation efficiency $(6.6 \%)$ is higher with callus induced from inflorescence using Agrobacterium $^{[83]}$. However, this depends on the tissues and organs selected for infection and also genotypic sources, and the optimum conditions appropriate for transformation of different foxtail millet genotypes are still being explored. Liu et al. ${ }^{[83]}$ established a stable transformation system using Agrobacterium LBA4404 harboring the plasmid pBI121 containing the GUS ( $\beta$-glucuronidase) gene and obtained transgenic plants from cvs Jigu 11 and Yugu 2. Diao et al. ${ }^{[84]}$, Muthamilarasan and Prasad ${ }^{[85]}$ reviewed the 
recent development in this area in greater detail. Despite these developments, at present, there are few, if any, reports of research on foxtail millet quality at the molecular level.

Most research on the appearance quality of foxtail millet at the genetic level has focused on seed and millet color. The $\mathrm{F}_{2}$ and $\mathrm{F}_{3}$ populations from crossing Setaria italica B100 and Setaria viridis A10, were analyzed using RFLPs for loci related to these traits ${ }^{[86]}$. The results demonstrated that seed color is controlled by three genes $B, I$ and $K$. $B$ and $I$ are located on chromosome 7 and 9, respectively, while $K$ has not yet been mapped. Seeds are gray, if a homozygous dominant gene $B B$ is present alone, and seeds homozygous for $I I$ have a deeper color. The seed color of the $K K$ genotype is dark yellow. The BBIIKK genotype results in black seed color, whereas the homozygous recessive genotype of bbiikk results in white seed color. A proportion of genes controlling millet color have been located, with the gene for white millets on chromosome 4 , and gray millets on chromosome $6^{[87]}$.

The non-glutinous-glutinous property of millet is controlled by a single gene located on chromosome 4 . The dominant gene $W x$ codes for non-glutinous millet and the recessive gene of $w x$ results in glutinous millet ${ }^{[88]}$. A key gene encoding lycopene $\beta$-cyclase has recently been cloned successfully and lays the foundation for future research on carotenoid biosynthesis and pro-vitamin A content of foxtail millet ${ }^{[89]}$. A cDNA encoding a lipid transfer protein has been isolated from a foxtail millet cDNA library ${ }^{[90]}$. Proteins in this group may be involved in food allergies and in the plant can be related to surface wax formation, adaptation to the environment, and pathogen defense.

\section{Status of foxtail millet breeding for quality}

As a minor cereal, foxtail millet is cultivated in limited areas. Since it is consumed mostly as a supplementary food, high quality is sought by consumers. Therefore, the main breeding objective since the end of the last century has shifted from high yield to high quality ${ }^{[91-93]}$. A few cultivars and landraces, such as cvs Jingu 21 and Jingumi have been developed into outstanding trademarked products, and several other new cultivars (Jingu 34, Jigu 17, Yugu 9 and Jiugu 11), which achieve a compromise between good quality and high yield, have been developed ${ }^{[3]}$.

Cross breeding is the most commonly used and effective breeding method ${ }^{[94]}$. At present, most high-quality cultivars are selected from filial generations. For example, Changgu 1 and Changnong 35 were selected through the cross breeding of Jingu 21 with two other high quality cultivars-Qitouhuang and Ninghuang 1, respectively.
Use of radiation induced mutagenesis in breeding programs has also produced some excellent cultivars such as Jingu $21^{[95]}$, Longfu 93-076 ${ }^{[96]}$ and Chigu $4^{[97]}$. Jingu 21, which was developed following ${ }^{60} \mathrm{Co} \gamma$ irradiation of Jinfen 52, has been regarded as the highest quality cultivar. Trait-targeted gene bank breeding is a new method of transgression breeding, which uses the additive effect of genes from the gene bank by integration of quality related genes through successive crossings, generating cultivars with high quality and improved health functions, for example cvs Jigu 21, Chaozaoshu 2 and Jigu 32 $2^{[58,98]}$.

\section{Problems and prospects for research on foxtail millet quality}

Foxtail millet is widely recognized for its adaptive potential and high nutritional value. In recent years, the focus has been on research regarding millet quality, from which several urgent issues emerge. These need to be addressed in order to promote breeding for quality: (1) Current evaluation systems have their limitations. An improved evaluation methodology that is both accurate and convenient for gauging foxtail millet quality would promote breeding for quality and as well as marketing. (2) There is a lack of high throughput methods for simple and rapid screening to identify good quality resources from large foxtail millet germplasm collections. Large scale testing for nutritional quality can be achieved rapidly with single grains of foxtail millet using near-infrared diffuse reflectance spectroscopy. However, it is difficult to screen for appearance, and cooking or flavor attributes because of the requirement of large sample sizes, heavy workload and high cost. (3) There have been some reports on foxtail millet nutrient content, however more comprehensive analysis is needed, particularly for the effects of growing conditions and agronomic methods on nutrients. (4) Germplasm resources of good quality foxtail millet are limited, and this narrow genetic diversity strongly restricts breakthroughs in quality breeding. (5) There is a lack of molecular markers for quality traits, and therefore the only means for selecting high quality millet is assessment of appearance. Rapid generation of molecular markers should be a priority.

The way forward is to take full advantage of the genome sequence, to understand molecular mechanisms underlying millet quality, and to identify genes and markers by a genome wide association study on a pool of accessions with diverse traits in millet quality, or mapping through recombinant inbred lines, as has proved successful in other crops ${ }^{[99,100]}$. In addition, the genomes and transcriptome of the higher quality cultivars produced by irradiation could be compared to the original cultivars to identify candidate genes for quality traits. Molecular markers could then be used to identify lines with high quality at an early growth 
stage, which would not only enhance the accuracy of selection but also significantly reduce the workload, time and cost.

Acknowledgements We would like to thank Prof. Donald Grierson, Dr. Rupert Fray and Miss Natalia Przelomska for their help with the manuscript. This work was supported by the National Natural Science Foundation of China (31371693, 31471502, 31471556), Shanxi Key Project (20120311005-3), Shanxi Science and Technology Platform fund (2012091004-0103), Research Project Supported by Shanxi Scholarship Council of China for Oversea Returnees (2010041, 2010050), the Joint Specialized Research Fund for the Doctoral Program of Higher Education, Ministry of Education (20131403110001).

Compliance with ethics guidelines $\mathrm{Lu} \mathrm{He}$, Bin Zhang, Xingchun Wang, Hongying Li and Yuanhuai Han declare that they have no conflict of interest or financial conflicts to disclose.

This article is a review and does not contain any studies with human or animal subjects performed by any of the authors.

\section{References}

1. Yang X, Wan Z, Perry L, Lu H, Wang Q, Zhao C, Li J, Xie F, Yu J, Cui T, Wang T, Li M, Ge Q. Early millet use in northern China. Proceedings of the National Academy of Sciences of the United States of America, 2012, 109(10): 3726-3730

2. Gai J. Millet breeding. In: Gai J, ed. Crop breeding science. Beijing: China Agriculture Press, 2003, 200-201 (in Chinese)

3. Diao X. Current status of foxtail millet production in China and future development directions. In: Diao X, ed. Foxtail millet production in China and the industrial technology system. Beijing: China Agricultural Science and Technology Press, 2011, 20-30 (in Chinese)

4. Diao X, Zhang X, Cheng R, Guo E, Guan Y, Yang T, Wang H, Li $\mathrm{S}$. Analysis of technical obligation for foxtail millet development in China - a survey report on foxtail millet production. In: Diao X, ed. Foxtail millet production in China and the industrial technology system. Beijing: China Agricultural Science and Technology Press, 2011, 3-19 (in Chinese)

5. Song D, Gao D. Nutritional value and product development of foxtail millet. Grain Processing, 2005, 30(1): 21-24 (in Chinese)

6. Feng N, Wei T, Zheng H, Hou D, Li J, Yang C. Study on technique to increase the value of superior quality foxtail millet 'Fenzhouxiang' and its byproducts. In: Diao X, ed. Foxtail millet production in China and the industrial technology system. Beijing: China Agricultural Science and Technology Press, 2011, 349-352 (in Chinese)

7. Li P, Zhang W, Lu M, Yang B, Zhang A, Zhang X. The development of a convenient and nutritious foxtail millet powder. In: Diao X, ed. Foxtail millet production in China and the industrial technology system. Beijing: China Agricultural Science and Technology Press, 2011, 364-367 (in Chinese)

8. Li J, Meng Z, Yang G, Ma H, Wang C, Yang X. Discussion on super quality foxtail millet production. In : Diao X, ed. Foxtail millet production in China and the industrial technology system. Beijing: China Agricultural Science and Technology Press, 2011, 328-331 (in Chinese)

9. Saleh A S M, Zhang Q, Chen J, Shen Q. Millet grains: nutritional quality, processing, and potential health benefits. Comprehensive Reviews in Food Science and Food Safety, 2013, 12(3): 281-295

10. Thathola A, Srivastava S, Singh G. Effect of foxtail millet supplementation on serum glucose, serum lipids and glycosylated hemoglobin in type 2 diabetics. Diabetologia Croatica, 2011, 40 (1): 23-28

11. Li Z, Li Q, Sun W, Song Y, Huo C, Wang G, Wang M. Study on evaluation methods of millet taste (palatability). Chinese Agricultural Science Bulletin, 2009, 25(15): 46-50 (in Chinese)

12. Wang R. Study on cooking and eating quality of foxtail millet. In: Li D, ed. Breeding technology of new foxtail millet varieties. Xi'an: Tian Ze Press, 1990, 18-24 (in Chinese)

13. Hebei Academy of Agriculture and Forestry Sciences. The high quality of edible millet and the detection methods. Local standards in Hebei Province: DB/1300 B22, 1990, 13-90 (in Chinese)

14. Wang B, Jiang K, Jing M, Wang M, Zhang F. Selecting highquality millet by quantification of indicators. Chinese Agricultural Science Bulletin, 2010, 26(1): 62-66 (in Chinese)

15. Li X. How to identify millet quality. Farm Products Processing, 2012, (2): 27 (in Chinese)

16. Wang H, Yin W, Yang Y, Chen H. Primary study on millet yellow pigment - study on chemical constituents and application of millet yellow pigment. Journal of the Chinese Cereals and Oils Association, 2004, 19(3): 26-30 (in Chinese)

17. Tan G, Jiang L, Han Y. Study on extracting and stability of edible yellow pigment from Setaria italica (L.) Beauv. Guangdong Food Science and Technology, 2004, 20(3): 54-55 (in Chinese)

18. Wang H, Tian Z, Yang Y, Chen H. Study on millet yellow pigmentextraction and pigment stability. Journal of the Chinese Cereals and Oils Association, 2005, 20(5): 40-45 (in Chinese)

19. Yang Y, Guan Y, Qin L, Shi H, Wang H, Zhang H. The studies on yellow pigment content and appearance quality of millet from different regions. Journal of the Chinese Cereals and Oils Association, 2012, 27(1): 14-19 (in Chinese)

20. Wang Y, Li H, Tian G, Sun M, Shi Q, Guo E. Relationship between cooked millet palatability and both visual quality and RVA profile character of starch. Journal of Shanxi Agricultural Sciences, 2008, 36(7): 34-39 (in Chinese)

21. Han J, Zhang A, Luo M, Zhang S, Ping H, Wang H. Analysis and evaluation of starch content in "Zhangzagu" millet. Hebei Journal of Industrial Science \& Technology, 2012, 29(1): 23-26 (in Chinese)

22. Zhao S, Li H, Wu F, Li P. Preliminary study on quantitative indicators of foxtail millet eating quality. Crop Germplasm Resources, 1989, (3): 34-35 (in Chinese)

23. Zhao S, Li H, Li P. Direct measurement methods for foxtail millet gelatinization temperature. Journal of Shanxi Agricultural Sciences, 1988, (3): 11-14 (in Chinese)

24. Liu H, Zhang M. Relationship between amylose content and gelatinization characteristics of different varieties of millet. Food Science, 2010, 31(15): 31-33 (in Chinese) 
25. Ma J, Li Y, Li H, Zhang M, Liu W. Analysis of relationship between RVA stickiness and different amylose content in spring millet. Journal of Northeast Agricultural University, 2009, 40(12): 5-8 (in Chinese)

26. Liu J, Liu S, Zhao W, Zuo X, Zhang Y. Analysis and study on volatile flavor compounds in millet porridge. Cereal and Feed Industry, 2010, (11): 31-33 (in Chinese)

27. Liu J, Liu S, Zhao W, Li Y, Zhang Y. Influence of different water addition on volatile flavor compounds of millet porridge. Food Research and Development, 2011, 32(9): 5-8 (in Chinese)

28. Liu J, Liu W, Liu C, Zhang Y, Liu Y. Volatile flavor compounds of non-glutinous millet porridge and glutinous millet porridge. Food Science and Technology, 2011, 36(3): 272-276 (in Chinese)

29. Yan S, Qian A, Song Y, Lin Q, Lin X. Content of amino acids in cereal protein and its nutritive evaluation. Chinese Agricultural Science Bulletin, 2009, 25(18): 113-117 (in Chinese)

30. Yang $\mathrm{C}$, Li H, Deng X, Tian Z, Wang H. The amino acid composition of protein in millet and quality evaluation. Academic Periodical of Farm Products Processing, 2008, (12): 8-10 (in Chinese)

31. Gu S, Gu X, Geng J. Effects of different soils and altitudes on the composition of amino acids in foxtail millet. Eco-agriculture Research, 2000, 8(3): 32-35 (in Chinese)

32. Zhang L, Lu P, Cao R. Analysis of amino acid components in main cereals. Amino Acids and Biotic Resources, 1989, (3): 30-32 (in Chinese)

33. Yang Y, Zhang H, Qin L, Wang H, Guan Y, Duan N, Zhang H. Polymorphism analysis of seed storage proteins in foxtail millet [Setaria italica (L.) Beauv] with A-PAGE. Acta Agronomica Sinica, 2009, 35(7): 1374-1378 (in Chinese)

34. Liu J, Wang S, Lu Z, Yan H, Liu H, Jiang Z, Song Z. Primary discussion on the industrialized development of foxtail millet. In: Diao X, ed. Foxtail millet production in China and the undustrial technology system. Beijing: China Agricultural Science and Technology Press, 2011, 111-113 (in Chinese)

35. Taira H. Amino acid composition of different varieties of foxtail millet (Setaria italica). Journal of Agricultural and Food Chemistry, 1968, 6(6): 1025-1027

36. Tian Z, Wang H, Sun Q, Deng X, Li H, Yang C. Study of the characteristics and quality of millet and the properties of amino acid. Innovational Edition of Farm Products Processing, 2009, (6): 21-22 (in Chinese)

37. Liu W, Lu B, Zhou N. Studies on the effects of various ecological factors on the contents of protein and fat in millet. Journal of Shanxi Agricultural University, 1995, 15(3): 244-247 (in Chinese)

38. Liu F, Yu S, Tang Z, Ye M. Study on millet fatty acid content in China. Journal of Agricultural University of Southwest, 1997, 19 (4): 371-374 (in Chinese)

39. Li P, Zhang W, Zhang A, Lu M, Zhang X. Nutritional value and promotion of foxtail millet. In: Niu X, Liu Z, ed. Proceeding of the fourth Chinese minor cereals industrial development conference. Beijing : China Agricultural Science and Technology Press, 2007 (in Chinese)

40. Gu S, Liu Z, Li L. A study on protein and fat contents and their interrelation in various varieties of foxtail millet in Shanxi
Province. Acta Agriculturae Boreali-Sinica, 1986, 1(4): 15-20 (in Chinese)

41. He J, Yang T, Wu G. Evaluation on nutritive quality of local varieties for foxtail millet in Gansu Province. Journal of Plant Genetic Resources, 2002, 3(1): 41-44 (in Chinese)

42. Liu X, Li X. Study on quality characters of foxtail millet in Jilin Province. Journal of Jilin Agriculture Sciences, 1993, (1): 12-13 (in Chinese)

43. Wei L, Wang T, Zhang G. A study on protein and fat contents and characterization of disease resistance in millet varieties. Acta Agriculturae Boreali-Sinica, 1999, 14(2): 1-5 (in Chinese)

44. Wang H, Xia J. Millet nutritional ingredients and the product research and development progress. Grain Science and Technology and Economy, 2010, 35(4): 36-38 (in Chinese)

45. Liang S, Yang G, Ma Y. Chemical characteristics and fatty acid profile of foxtail millet bran oil. Journal of the American Oil Chemists' Society, 2010, 87(1): 63-67

46. Zhang C, Zhang H, Li J. Advances of millet research on nutrition and application. Journal of the Chinese Cereals and Oils Association, 2007, 22(1): 51-55 (in Chinese)

47. Liu C, Zhang P, Shen Q. Study on the starch properties of nine varieties of millet in Hebei Province. Science and Technology of Food Industry, 2010, 31(1): 81-84 (in Chinese)

48. Krishna Kumari S, Thayumanavan B. Characterization of starches of proso, foxtail, barnyard, kodo, and little millets. Plant Foods for Human Nutrition, 1998, 53(1): 47-56

49. Ma L, Li X, Lu F. Study on pasting properties between millet starch and maize starch. Journal of Cereals and Oils, 2005, (2): 22-25 (in Chinese)

50. Yang Y, Qin L, Guan Y, Wang H, Zhang H. Effect of sowing date on the nutrient components of millet. Journal of Hebei Agricultural Sciences, 2010, 14(11): 19-21, 27 (in Chinese)

51. He J, Dong K, Yang T. Effect of water-controlled irrigation on quality characters of foxtail millet in arid area. Ganhan Diqu Nongye Yanjiu, 2008, 26(3): 55-58 (in Chinese)

52. Bangoura M L, Nsor-Atindana J, Ming Z, Wei P, Mothibe K J, Xue Z. Starch functional properties and resistant starch from foxtail millet [Setaria italica (L.) P. Beauv] species. Pakistan Journal of Nutrition, 2012, 11(10): 821-830

53. Itagi $\mathrm{S}$, Naik R, Bharati $\mathrm{P}$, Sharma P. Readymade foxtail millet mix for diabetics. International Journal of Science and Nature, 2012, 3 (1): $47-50$

54. Hathan B S, Prassana B L. Optimization of fiber rich gluten-free cookie formulation by response surface methodology. World Academy of Science, Engineering and Technology, 2011, 5(12): 669-678

55. Liu X, Zhang A, Wang G, Wang H. Study on effects of varieties and regions factors on content of $\mathrm{Fe}, \mathrm{Zn}, \mathrm{Mg}$ and $\mathrm{Se}$ in millet. Journal of Hebei Agricultural Sciences, 2011, 15(10): 7-10,108 (in Chinese)

56. Liu S, Zhu Z, Li W, Liu F, Li Y, Huang R. Evaluation of selenium and protein content of foxtail millet landraces originated from different ecological regions of China. Scientia Agricultura Sinica, 2009, 42(11): 3812-3818 (in Chinese)

57. Wang Y, Wang W. Primary investigation for millet nutritional 
ingredient in China. Crop Germplasm Resources, 1986, (4): 29-31 (in Chinese)

58. Liu Z, Cheng R. Establishment and application of breeding technology system on millet target character gene bank. Scientia Agricultura Sinica, 2005, 38(7): 1306-1311 (in Chinese)

59. Shao L, Wang L, Bai W, Liu Y. Evaluation and analysis of folic acid content in millet from different ecological regions of Shanxi Province. Scientia Agricultura Sinica, 2014, 47(7): 1265-1272 (in Chinese)

60. Zhang G, Liu X, Quan Z, Cheng S, Xu X, Pan S, Xie M, Zeng P, Yue Z, Wang W, Tao Y, Bian C, Han C, Xia Q, Peng X, Cao R, Yang X, Zhan D, Hu J, Zhang Y, Li H, Li H, Li N, Wang J, Wang C, Wang R, Guo T, Cai Y, Liu C, Xiang H, Shi Q, Huang P, Chen Q, Li Y, Wang J, Zhao Z, Wang J. Genome sequence of foxtail millet (Setaria italica) provides insights into grass evolution and biofuel potential. Nature Biotechnology, 2012, 30(6): 549-554

61. Bennetzen J L, Schmutz J, Wang H, Percifield R, Hawkins J, Pontaroli A C, Estep M, Feng L, Vaughn J N, Grimwood J, Jenkins J, Barry K, Lindquist E, Hellsten U, Deshpande S, Wang X, Wu X, Mitros T, Triplett J, Yang X, Ye C Y, Mauro-Herrera M, Wang L, Li P, Sharma M, Sharma R, Ronald P C, Panaud O, Kellogg E A, Brutnell T P, Doust A N, Tuskan G A, Rokhsar D, Devos K M. Reference genome sequence of the model plant Setaria. Nature Biotechnology, 2012, 30(6): 555-561

62. Li G, Zhu Z, Li W. Progress on molecular genetics of foxtail millet (Setaria italica). Journal of Plant Genetic Resources, 2008, 9(4): 556-560 (in Chinese)

63. Wang C, Chen J, Zhi H, Yang L, Li W, Wang Y, Li H, Zhao B, Chen M, Diao X. Population genetics of foxtail millet and its wild ancestor. BMC Genetics, 2010, 11(1): 90

64. Wang C, Jia G, Zhi H, Niu Z, Chai Y, Li W, Wang Y, Li H, Lu P, Zhao B, Diao X. Genetic diversity and population structure of Chinese foxtail millet [Setaria italica (L.) Beauv.] landraces. Genes Genomes Genetics, 2012, 2(7): 769-777

65. Zhu X, Zhang Y, Song Y, Zhao Z, Liu Z, Shi Y, Li Y, Wang T. Genetic diversity analysis of foxtail millet accessions revealed by SSR markers. Journal of Plant Genetic Resources, 2010, 11(6): 698-702 (in Chinese)

66. Jia G, Huang X, Zhi H, Zhao Y, Zhao Q, Li W, Chai Y, Yang L, Liu K, Lu H, Zhu C, Lu Y, Zhou C, Fan D, Weng Q, Guo Y, Huang T, Zhang L, Lu T, Feng Q, Hao H, Liu H, Lu P, Zhang N, Li Y, Guo E, Wang S, Wang S, Liu J, Zhang W, Chen G, Zhang B, Li W, Wang Y, Li H, Zhao B, Li J, Diao X, Han B. A haplotype map of genomic variations and genome-wide association studies of agronomic traits in foxtail millet (Setaria italica). Nature Genetics, 2013, 45(8): 957-961

67. Pandey G, Misra G, Kumari K, Gupta S, Parida S K, Chattopadhyay D, Prasad M. Genome-wide development and use of microsatellite markers for large-scale genotyping applications in foxtail millet [Setaria italica (L.)]. DNA Research, 2013, 20(2): 197-207

68. Zhang S, Tang C, Zhao Q, Li J, Yang L, Qie L, Fan X, Li L, Zhang N, Zhao M, Liu X, Chai Y, Zhang X, Wang H, Li Y, Li W, Zhi H, Jia G, Diao X. Development of highly polymorphic simple sequence repeat markers using genome-wide microsatellite variant analysis in Foxtail millet [Setaria italica (L.) P. Beauv]. BMC Genomics, 2014, 15(1): 78

69. Kumari K, Muthamilarasan M, Misra G, Gupta S, Subramanian A, Parida S K, Chattopadhyay D, Prasad M. Development of eSSRmarkers in Setaria italica and their applicability in studying genetic diversity, cross-transferability and comparative mapping in millet and non-millet species. PLoS ONE, 2013, 8(6): e67742

70. Yadav C B, Muthamilarasan M, Pandey G, Khan Y, Prasad M. Development of novel microRNA-based genetic markers in foxtail millet for genotyping applications in related grass species. Molecular Breeding, 2014, 34(4): 2219-2224

71. Yadav C B, Bonthala V S, Muthamilarasan M, Pandey G, Khan Y, Prasad M. Genome-wide development of transposable elementsbased markers in foxtail millet and construction of an integrated database. DNA Research, 2015, 22(1): 79-90

72. Bonthala V S, Muthamilarasan M, Misra G, Prasad M. FmMDb: a versatile database of foxtail millet markers for millets and bioenergy grasses research. PLoS ONE, 2013, 8(8): e71418

73. Li Z, Hao Z, Liu L, Dong Z, Dong J. Molecular cloning and preliminary analysis of Clmk-1 gene in Cochliobolus Lunatus. Acta Agriculturae Boreali-Sinica, 2012, 27(3): 41-45 (in Chinese)

74. Lata C, Sahu P P, Prasad M. Comparative transcriptome analysis of differentially expressed genes in foxtail millet (Setaria italica L.) during dehydration stress. Biochemical and Biophysical Research Communications, 2010, 393(4): 720-727

75. Min D, Xue F, Ma Y, Chen M, Xu Z, Li L, Diao X, Jia G, Ma Y. Characteristics of PP2 gene family in foxtail millet (Setaria italica). Acta Agronomica Sinica, 2013, 39(12): 2135-2144

76. Qi X, Xie S, Liu Y, Yi F, Yu J. Genome-wide annotation of genes and noncoding RNAs of foxtail millet in response to simulated drought stress by deep sequencing. Plant Molecular Biology, 2013, 83(4-5): 459-473

77. Wang M, Li P, Li C, Pan Y, Jiang X, Zhu D, Zhao Q, Yu J. SiLEA14, a novel atypical LEA protein, confers abiotic stress resistance in foxtail millet. BMC Plant Biology, 2014, 14(1): 290

78. Mauro-Herrera M, Wang X, Barbier H, Brutnell T P, Devos K M, Doust A N. Genetic control and comparative genomic analysis of flowering time in Setaria (Poaceae). Genes Genomes Genetics, 2013, 3(2): 283-295

79. Wang Y, Li W, Diao X. Genetic transformation of foxtail millet mediated by Agrobacterium tumefaciens. Journal of Hebei Agricultural Sciences, 2003, 7(4): 1-6 (in Chinese)

80. Brutnell T P, Wang L, Swartwood K, Goldschmidt A, Jackson D, Zhu X G, Kellogg E, Van Eck J. Setaria viridis: a model for C4 photosynthesis. Plant Cell, 2010, 22(8): 2537-2544

81. Diao X, Chen Z, Duan S, Liu Y, Zhao L, Sun J. Factors influencing foxtail millet embryogenic calli transformation by particle bombardments. Acta Agriculturae Boreali-Sinica, 1999, 14(3): 31-36 (in Chinese)

82. Dong Y, Duan S, Zhao L, Yang X, Jia S. Production of transgenic millet and maize plants by particle bombardment. Scientia Agricultura Sinica, 1999, 32(2): 1-7 (in Chinese)

83. Liu Y, Yu J, Ao G, Zhao Q. Factors influencing agrobacteriummediated transformation of foxtail millet (Setaria italica). Chinese Journal of Biochemistry and Molecular Biology, 2007, 23(7): 531- 
536 (in Chinese)

84. Diao X, Schnable J, Bennetzen J L, Li J. Initiation of setaria as a model plant. Frontiers of Agricultural Science and Engineering, 2014, 1(1): 16-20

85. Muthamilarasan M, Prasad M. Advances in Setaria genomics for genetic improvement of cereals and bioenergy grasses. Theoretical and Applied Genetics, 2015, 128(1): 1-14

86. Wang Z, Devos K M, Liu C, Wang R, Gale M D. Construction of RFLP-based maps of foxtail millet (Setaria italica). Theoretical and Applied Genetics, 1998, 96(1): 31-36 (in Chinese)

87. Wang R, Gao J, Guan Z, Mao L. Chromosome mapping and linkage analysis of a few agronomical important traits in foxtail millet. Acta Agronomica Sinica, 2007, 33(1): 9-14 (in Chinese)

88. Wang R, Gao J, Mao L. Chromosomal mapping of genes controlling glutinousness, dwarfness and grey millet traits in foxtail millet. Journal of Yunnan University, 1999, 21(S3): 111112 (in Chinese)

89. Zhao Q, Lai F, Yu J, Zhu D, Ao G. Cloning of lycopene $\beta$-cyclase gene related to carotenoid biosynthetic pathway of millet (Setaria italica). Journal of Plant Genetic Resources, 2010, 11(6): 698-702 (in Chinese)

90. Feng X, Yu J, Zhao Q, Ao G. Cloning and characterization of a Setaria italica lipid transfer protein cDNA. Journal of Agricultural Biotechnology, 2003, 11(1): 11-15 (in Chinese)

91. Pan Z, Li K, Zhao L, Zhou H. Review and prospects of foxtail millet breeding in Zhangye City Academy. China Seed Industry, 2012, (7): 17-18 (in Chinese)

92. Sang P. Analysis on breeding development of spring foxtail millet in Shanxi Province. Agriculture Science and Technology and
Communication, 2011, (12): 8-9 (in Chinese)

93. Wang S. Reviews and prospects of foxtail millet breeding in Heilongjiang Province. China Agricultural Technology Extension, 2008, 24(6): 15-39 (in Chinese)

94. Wang L, Wang X, Wen Q. Breeding and high-yield cultivation technique in high-quality millet varieties. Journal of Shanxi Agricultural Sciences, 2008, 36(11): 53-56 (in Chinese)

95. Chen Y, Wei T. Breeding and promotion prospect of Jingu 21. Journal of Shanxi Agricultural Sciences, 1992, (12): 7-8 (in Chinese)

96. Yi H, Yu H, Ma J. A review on the development of irradiation breeding of millet in China. Acta Agriculturae Nucleatae Sinica, 2002, 16(2): 125-128 (in Chinese)

97. Li B, Li S, Jiang S. Breeding and utilization of new foxtail millet variety-Chigu 4. Inner Mongolia Agricultural Science and Technology, 1990, (4): 1-2 (in Chinese)

98. Li S, An S, Liu Z, Cheng R, Wang Z. Innovation of the new superior quality foxtail millet [Setaria italica (L.) P. Beauv] variety - Jigu32 with characteristics of stress resistance, stable and high yield and its physiological mechanism. Agricultural Sciences, 2014, 5(4): 304-316 (in Chinese)

99. Mansur L M, Orf J H, Chase K, Jarvik T, Cregan P B, Lark K G. Genetic mapping of agronomic traits using recombinant inbred lines of soybean. Crop Science, 1996, 36(5): 1327-1336

100. Zhang Y, Wu Y, Xiao Y, Yan J, Zhang Y, Zhang Y, Ma C, Xia X, He Z. QTL mapping for milling, gluten quality, and flour pasting properties in a recombinant inbred line population derived from a Chinese soft $\times$ hard wheat cross. Crop and Pasture Science, 2009, 60(6): $587-597$ 